\title{
Endoscopic removal of an over-the-scope clip using endoscopic submucosal dissection technique
}

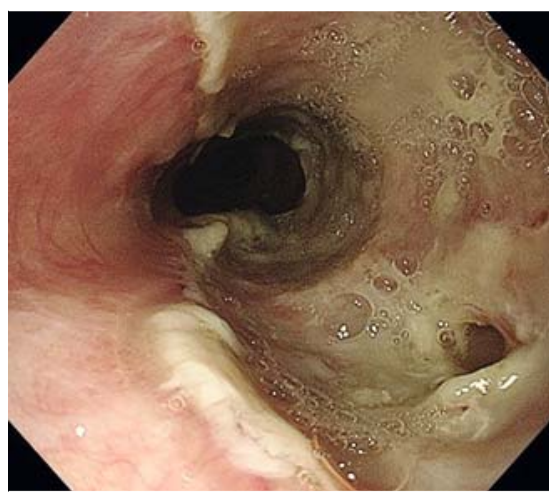

- Fig. 1 Delayed perforation was identified on the defect after endoscopic submucosal dissection.

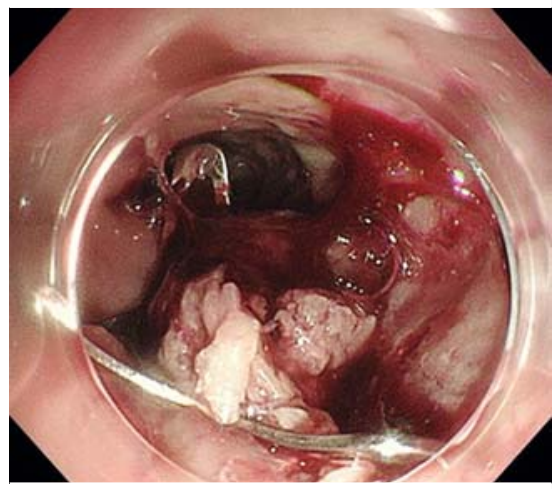

- Fig. 2 The perforation was closed with an over-the-scope clip.

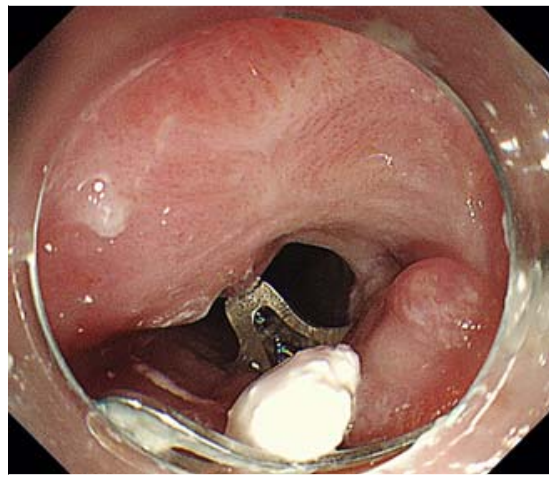

Fig. 3 A previously ingested tablet was seen resting on the over-the-scope clip.

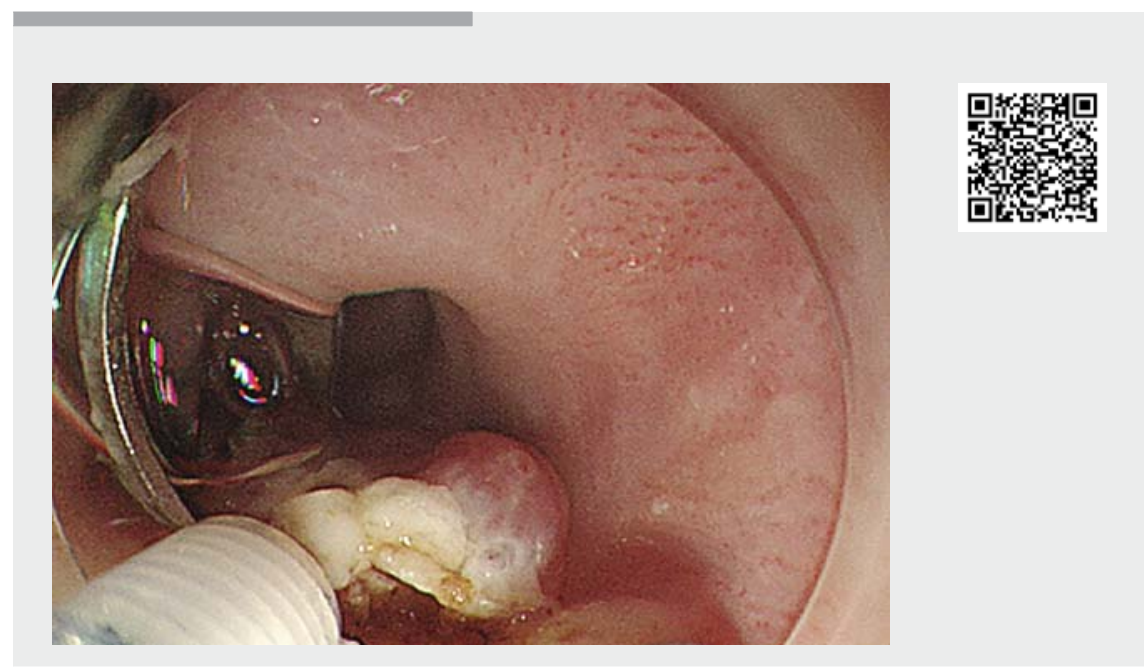

$\checkmark$ Video 1 Endoscopic removal of an over-the-scope clip using endoscopic submucosal dissection technique.

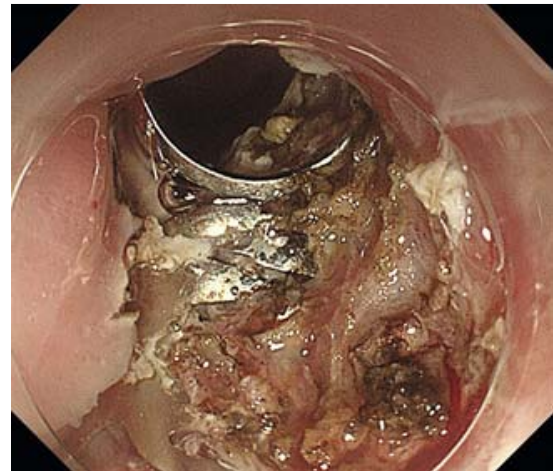

> Fig. 4 Most part of the over-the-scope clip was seen after removing the granulation tissue above it.

Over-the-scope (OTS) clips are widely used for endoscopic closure of perforations and fistulae [1]. OTS clip-associated complications include perforation, bleeding, infection, ulceration, and luminal stenosis and obstruction. Most OTS clips fall off within several weeks, but some persist and cause problems. Bipolar cutting devices and Nd: YAG-lasers have been reported to be useful in the removal of OTS clips [2-4]. However, in Japan, these devices are not commercially avail-

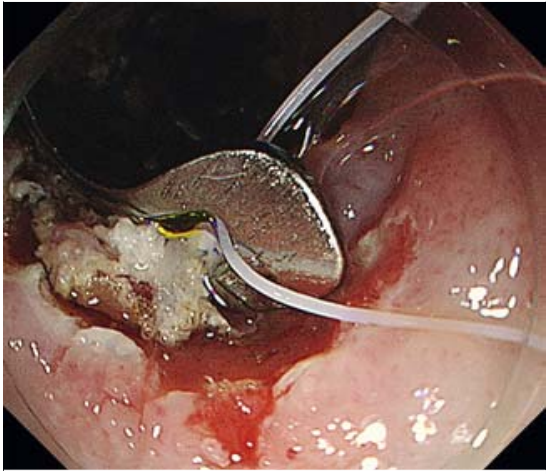

$\checkmark$ Fig. 5 A thread was attached to the oral side of the over-the-scope clip to create traction.

able. Inject-and-resect techniques for OTS clip removal on normal mucosa have also been reported [5]. Here, we report the first case of OTS clip removal on the scar via endoscopic submucosal dissection (ESD) without injection ( $\triangleright$ Video 1 ).

A 66-year-old man was diagnosed with recurrence of superficial esophageal cancer near the previous ESD scar. We performed ESD for this lesion; there was no apparent perforation. However, he complained of abdominal pain, and a com- 
puted tomography scan revealed mediastinum emphysema. Endoscopic examination on Day 3 post-ESD identified a perforation ( $\triangleright$ Fig. 1), which was closed with an OTS clip ( Fig. 2). After discharge, he complained of dysphagia (difficulty swallowing solid food), which was caused by a luminal stenosis. Endoscopic balloon dilation for the stenosis was performed 2 months after ESD. However, the symptoms persisted, and we decided to remove the clip after obtaining informed consent.

The endoscope could not pass and a previously ingested tablet was seen resting on the OTS clip ( $\triangleright$ Fig. 3 ). To expose the partially buried clip, we resected the granulation tissue above the clip using an electrosurgical endoknife (FlushknifeBT $1.5 \mathrm{~mm}$, DK2618JB; Fujifilm Medical, Tokyo, Japan) (> Fig.4). Using traction from a suspended thread attached to the oral part of the clip ( $>$ Fig.5), we cut just below the clip on the oral side. Eventually, we achieved complete removal of the clip orally without perforation. The endoscope could then pass freely to the stomach, and the dysphagia resolved.

Endoscopy_UCTN_Code_TTT_1AO_2AG

Competing interests

The authors declare that they have no conflict of interest.
The authors

Hirohisa Sakurai, Satoki Shichijo, Yoji

Takeuchi, Kotaro Waki, Takashi Kanesaka, Noriya Uedo, Tomoki Michida

Department of Gastrointestinal Oncology, Osaka International Cancer Institute, Osaka, Japan

Corresponding author

\section{Satoki Shichijo MD, PhD}

Department of Gastrointestinal Oncology, Osaka International Cancer Institute, 3-1-69, Otemae, Chuo-ku, Osaka, 541-8567, Japan Fax: +81-6-69451900

shichijiyou-tky@umin.ac.jp

\section{References}

[1] Wedi E, Gonzalez S, Menke D et al. One hundred and one over-the-scope-clip applications for severe gastrointestinal bleeding, leaks and fistulas. World J Gastroentero 2016; 22: 1844-1853

[2] Bauder M, Meier B, Caca K et al. Endoscopic removal of over-the-scope clips: clinical experience with a bipolar cutting device. United European Gastroenterol J 2017; 5: 479484

[3] Fahndrich M, Sandmann M, Heike M. Removal of over the scope clips (OTSC) with an Nd:YAG Laser. Z Gastroenterol 2011; 49: 579-583
[4] Schmidt A, Riecken B, Damm M et al. Endoscopic removal of over-the-scope clips using a novel cutting device: a retrospective case series. Endoscopy 2014; 46: 762-766

[5] Mudumbi A, Velazquez-Aviña J, Neumann H et al. Anchoring of self-expanding metal stents using the over-the-scope clip, and a technique for subsequent removal. Endoscopy 2014; 46: 1106-1109

Bibliography

Endoscopy 2021; 53: E361-E362

DOI 10.1055/a-1293-6637

ISSN 0013-726X

published online 19.11.2020

(c) 2020. Thieme. All rights reserved.

Georg Thieme Verlag KG, Rüdigerstraße 14, 70469 Stuttgart, Germany

\section{ENDOSCOPY E-VIDEOS}

https://eref.thieme.de/e-videos

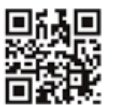

Endoscopy E-Videos is a free access online section, reporting on interesting cases and new techniques in gastroenterological endoscopy. All papers include a high quality video and all contributions are freely accessible online.

This section has its own submission website at https://mc.manuscriptcentral.com/e-videos 